\title{
Lysosomal acid lipase deficiency, a rare pathology
}

\author{
Catalina Gómez-Duarte, ${ }^{1}$ Víctor García, ${ }^{1}$ Verónica Botero, ${ }^{1}$ Ana Aristizabal, ${ }^{1}$ Gabriel Echeverri and \\ Harry Pachajoa ${ }^{3 *}$ \\ ${ }^{1}$ Fundación Valle de Lili. Cali; ${ }^{2}$ Clínica de la Costa, Universidad de la Sabana, Chia; ${ }^{3}$ Universidad Icesi, Cali. Colombia
}

\begin{abstract}
Lysosomal acid lipase deficiency is a genetic disease with a low prevalence and high morbidity and mortality in children and adults. It is characterized by an alteration of lipid metabolism, which generates cholesterol and triglyceride esters deposits in the body. Its clinical presentation depends on enzymatic activity. This condition should be suspected in patients with lipid or liver alterations after ruling out other diagnoses. Currently, there is the option of using a recombinant enzyme, which can improve lipid and liver parameters, as well as disease progression. Establishing a timely diagnosis in order to initiate specific treatment early is imperative for the prevention of morbidity and mortality. The purpose of this work is to perform a review of the literature about lysosomal acid lipase deficiency and to guide about its pathophysiology, clinical manifestations, diagnosis and treatment.
\end{abstract}

KEY WORDS: Dyslipidemia. Cirrhosis. Cholesterol esters deposition disease. Lysosomal acid lipase deficiency. Steatohepatitis. Cryptogenic liver disease.

\section{Introduction}

Lysosomal acid lipase (LAL; EC 3.1.13) is a glycoprotein that is mainly expressed in macrophages, hepatocytes, intestinal cells and Kupffer cells. It is encoded in the LIPA gene (MIM: 613497) located at chromosome 10 long arm (q), region 23.2-23.3. ${ }^{1-6}$ This glycoprotein acts as an enzyme that plays a key role in cholesterol metabolism. ${ }^{6}$

Cholesterol and triglyceride esters are transported in cholesterol lipoprotein particles, especially low density lipoproteins (LDL) and very low density lipoproteins (VLDL) to hepatocytes; they enter the cell through receptor-mediated (LDL-R) endocytosis until reaching the lysosome, where they are hydrolyzed by LAL to free cholesterol and free fatty acids. ${ }^{1-6}$ Free cholesterol inhibits 3-hydroxy-3-methyl-glutaryl-CoA reductase
(HMG-CoA) action, thus preventing cholesterol de novo formation, activation of proteins that bind to sterols regulatory elements and transcription factors responsible for the activation of cholesterol synthesis genes. ${ }^{6}$ Cholesterol plays an important role as a precursor in the synthesis of steroids and bile acids and as a component of cell membranes. ${ }^{6}$

Deficit of this enzyme (LAL-D; MIM: 278000) results in decreased hydrolysis and accumulation of cholesterol and triglyceride esters in liver lysosomes, blood vessels, the spleen, adrenal glands, hematopoietic system, lymph nodes and gastrointestinal tract. In addition, it is associated with reduced generation of free cholesterol and free fatty acids. ${ }^{1,3-10}$ The decrease in free cholesterol translates into sterol regulatory elements and HMG-CoA increased activity, with a corresponding increase in free cholesterol and free fatty acids synthesis. ${ }^{4,11}$ On the other hand, there is an
Date of reception: 12-12-2017

Date of acceptance: 18-07-2018

DOI: 10.24875/GMM.M19000272
Gac Med Mex. 2019;155:268-274

Contents available at PubMed www.gacetamedicademexico.com 


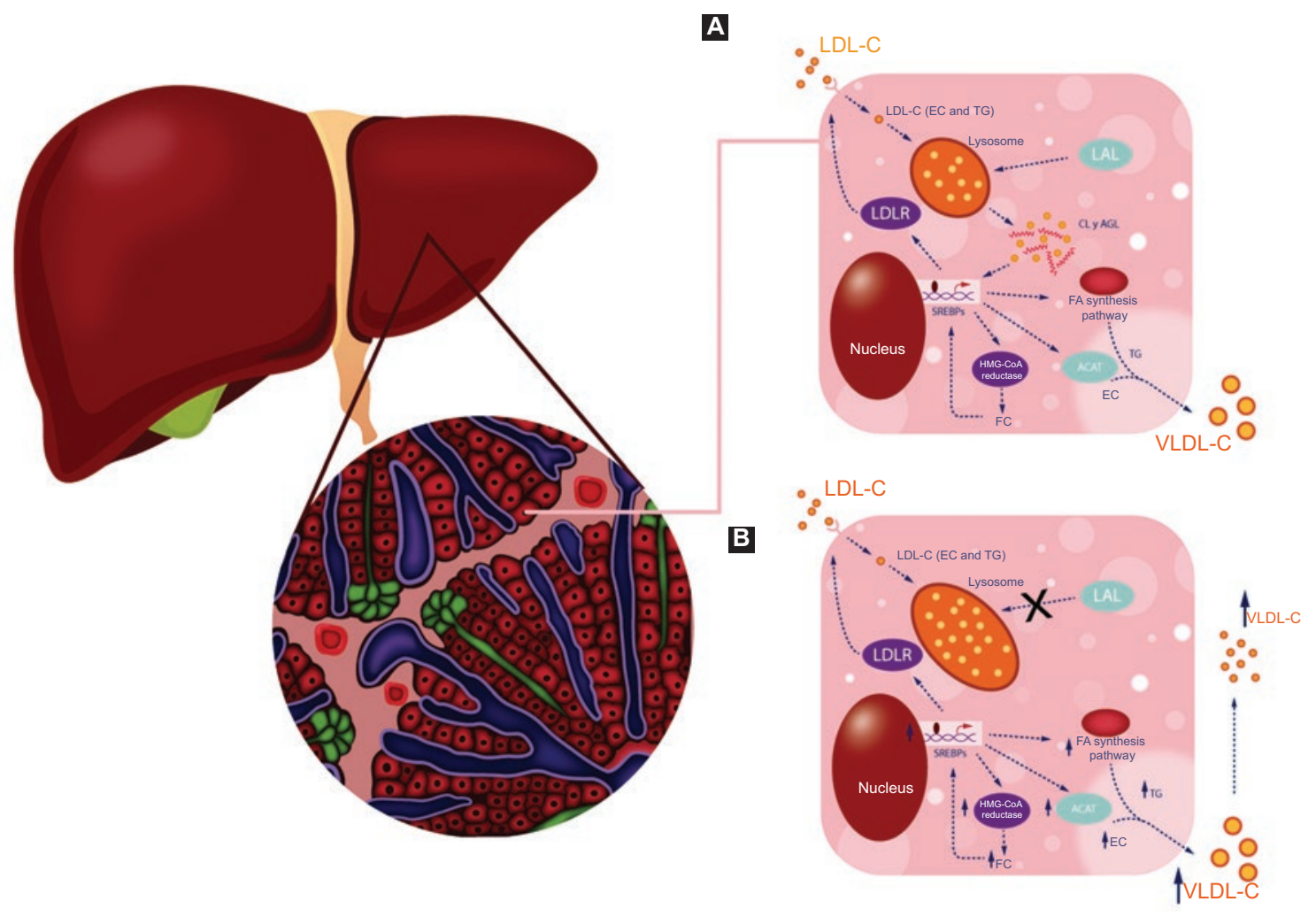

Figure 1. Diagram of cell cholesterol homeostasis A) in healthy individuals and B) in patients with lysosomal acid lipase deficiency. ACAT = acetyl-coenzyme $A$ acetyltransferase, $F A$ = fatty acids, FFA = free fatty acids, $E C=$ esterified cholesterol, $F C=$ free cholesterol, $L D L-C=l o w$-density lipoprotein cholesterol, VLDL-C = very low density lipoprotein cholesterol, HMG-CoA = hydroxy-methyl-glutaryl-coenzyme $A, L A L=I y s o s o m a l$ acid lipase, $L D L R=$ low-density lipoprotein receptor, SREBP = sterol regulatory element-binding proteins, $T G=$ triglycerides.

increase on VLDL cholesterol secretion and LDL levels. ${ }^{11,12}$ The decrease in free cholesterol reduces hepatic $X$ receptor activation, ABCA1 transporter expression and apolipoprotein $\mathrm{A} 1$ (ApoB100) and plasma HDL cholesterol flow ${ }^{12,13}$ (Figure 1).

LAL-D is an orphan disease, with an autosomal recessive transmission pattern. ${ }^{4,11,14,15}$ More than 50 mutations have been identified according to the Human Gene Mutation Data Base; exon 8- splicing site mutation, E8SJM (c.894G> A; p.del S275 Q298), is the most common, and it produces exon 8 deletion in mRNA. ${ }^{4-6,11,14-17}$ Previously, LAL-D was divided in two phenotypes, where enzymatic activity determines the clinical presentation: the childhood form, or Wolman disease, and one less severe form known as cholesterol ester storage disease ${ }^{-1,3,4,-10,18}$ in the first one, enzymatic activity is almost nil, while in the second there is residual enzymatic activity ( 1 to $12 \%$ of normal). ${ }^{12}$ Currently, this denomination is not used, since LAL-D is understood as the only nosological entity that has different presentation phenotypes, starting early and with rapid progression or with a late onset and variable progression ${ }^{11}$ (Table 1).
The purpose of this work is to carry out a review of the literature on LAL-D and provide guidance about its pathophysiology, clinical manifestations, diagnosis and treatment.

\section{Epidemiology}

The true prevalence of LAL-D is not known; however, it is assumed to range from 1 in 40,000 to 1 in 350,000 individuals according to the population. ${ }^{5,11,16,19-21}$ In Germany, prevalence was estimated at 1 among 50,000 cases of cholesterol ester storage disease and 1 in 350,000 cases of Wolman disease..$^{16,20}$ This disease occurs more frequently in individuals of Iranian-Jewish ancestry. According to Valles-Ayoub, the rate in this population is about 1 in 4200 people, which appears to correspond to a mutational variant associated with the entity (c.260G>T). ${ }^{22}$ The mutation of c.894G > A (E8SJM) is present in approximately 50 to $70 \%$ of patients with late LAL-D, which have residual activity of the enzyme. ${ }^{14,23}$ On the other hand, the mutations of C.892C> T (E8SJM-3) and C.894p1G>A 
Table 1. Lysosomal acid lipase deficiency phenotype

\begin{tabular}{|l|l|l|}
\hline Clinical manifestations & $\begin{array}{l}\text { Early form } \\
\text { (formerly WD) }\end{array}$ & $\begin{array}{l}\text { Late form } \\
\text { (CESD) }\end{array}$ \\
\hline Disease onset & First months of life & $\begin{array}{l}\text { From childhood } \\
\text { to adulthood }\end{array}$ \\
\hline Hepatomegaly & Marked & Variable \\
\hline Liver fibrosis & Present & Variable \\
\hline Splenomegaly & Present & Variable \\
\hline $\begin{array}{l}\text { Malabsorption } \\
\text { Adrenal calcifications }\end{array}$ & Marked & Variable \\
\hline $\begin{array}{l}\text { Dyslipidemia } \\
\text { Cholesterol ester storage } \\
\text { disease }\end{array}$ & $\begin{array}{l}\text { Variable }(5-160 \\
\text { times of normal) }\end{array}$ & $\begin{array}{l}\text { Present }(150-350 \\
\text { times of normal) }\end{array}$ \\
\hline WD $=$ Wolman disease; CESD $=$ cholesterol ester storage disease.
\end{tabular}

(E8SJMp1) have been detected in early-onset LAL-D. ${ }^{14,24}$

This disease affects both genders equally and has been reported more frequently in children, with a peak incidence at between three and 15 years of age. 12.25 There are phenotypes with mild manifestations that are not diagnosed due to the lack of suspicion and limited access to confirmatory diagnostic tests, which suggests that the real prevalence of the entity is higher. No studies have been reported on the prevalence of this disease either in Colombia or Latin America.

\section{Clinical manifestations}

Clinical manifestations are variable, with the most common including dyslipidemia, hepatomegaly and liver alterations. ${ }^{4}$ Early-onset LAL-D or Wolman disease is characterized by a severe and fulminant clinical presentation expressed in the first weeks of life. ${ }^{4-6,10,26-28}$ Clinically, these patients have chronic diarrhea (steatorrhea), vomiting, chronic malnutrition, malabsorption (due to steatorrhea and emetic episodes), failure to thrive, hepatosplenomegaly, liver compromise with development of fibrosis, cholestasis and liver failure. ${ }^{3-5,12,22,29}$ In addition, most of patients have adrenal gland bilateral calcification (50\%), which leads to adrenal primary insufficiency, multiple organ failure and death within the first year of life. . $^{3-5,22,29}$

Late-onset LAL-D or cholesterol ester storage disease is characterized by a more benign clinical presentation and a broad spectrum of manifestations. ${ }^{6}$ It can be asymptomatic until adulthood, during which hepatomegaly $(99 \%)$ with microvesicular or mixed hepatic steatosis, splenomegaly (74\%), gastrointestinal alterations and dyslipidemia occur, which generates early atherosclerosis with increased cardiovascular risk. $^{3-6,10,19,28-31}$ If the natural course of disease persists, chronic liver disease can cause liver failure, with the consequent need for liver transplantation. ${ }^{3-5-5,19,28-30}$

Due to the progressive accumulation of cholesterol and triglyceride esters, liver profile abnormalities are generated in both spectra, which are characterized by increased levels of serum transaminases (alanine aminotransferase $[\mathrm{ALT}]$ and aspartate aminotransferase [AST]), hyperbilirubinemia and dyslipidemia (increase in LDL, low levels of high-density lipoproteins [HDL] and increased triglycerides). ${ }^{3-6,12,22,29}$

\section{Diagnosis}

LAL-D recognition is difficult due to its low prevalence and to an overlapping with other diseases. In addition, the absence of clinical suspicion can lead to diagnostic errors, with a consequent disease progression and delay in treatment initiation.

In general, LAL-D should be suspected in patients with hepatosplenomegaly or hepatic or lipid profile alterations without a family history thereof. The diagnosis of this pathology should be established accordingly with the medical history, suggestive findings on physical examination and lipid profile results. Reiner et al. suggest that patients with lipid profile alterations who do not have a family history thereof should be assessed according to diagnostic criteria; should there be three or more clinical or paraclinical signs present, enzyme activity should be determined in blood ${ }^{4}$ (Figure 2).

Some diagnostic resources to support the diagnosis are liver biopsy and magnetic resonance imaging, which quantifies content of liver fat. ${ }^{12}$ On the other hand, liver biopsy shows liver morphology findings that can be suggestive but not confirmatory, such as microvesicular steatosis with Kupffer cell involvement, fibrosis, micronodular cirrhosis, sea-blue histiocytosis and cholesterol ester crystals. ${ }^{4,6,12,30,32,33}$ Other findings include lipid accumulation in reticuloendothelial cells of the spleen and vacuolated macrophages with lipids that infiltrate the lamina propria with gastrointestinal tissue architecture destruction and the consequent dysfunction of enterocytes absorbent and enzymatic activity. ${ }^{6}$ In immunohistochemical testing, cathepsin D lysosomal markers, and lysosomal membrane-associated proteins 1 and 2 (LAMP1 and LAMP2) can be used. ${ }^{32}$

Confirmatory diagnosis is established by measuring enzymatic activity in peripheral blood, skin fibroblasts 


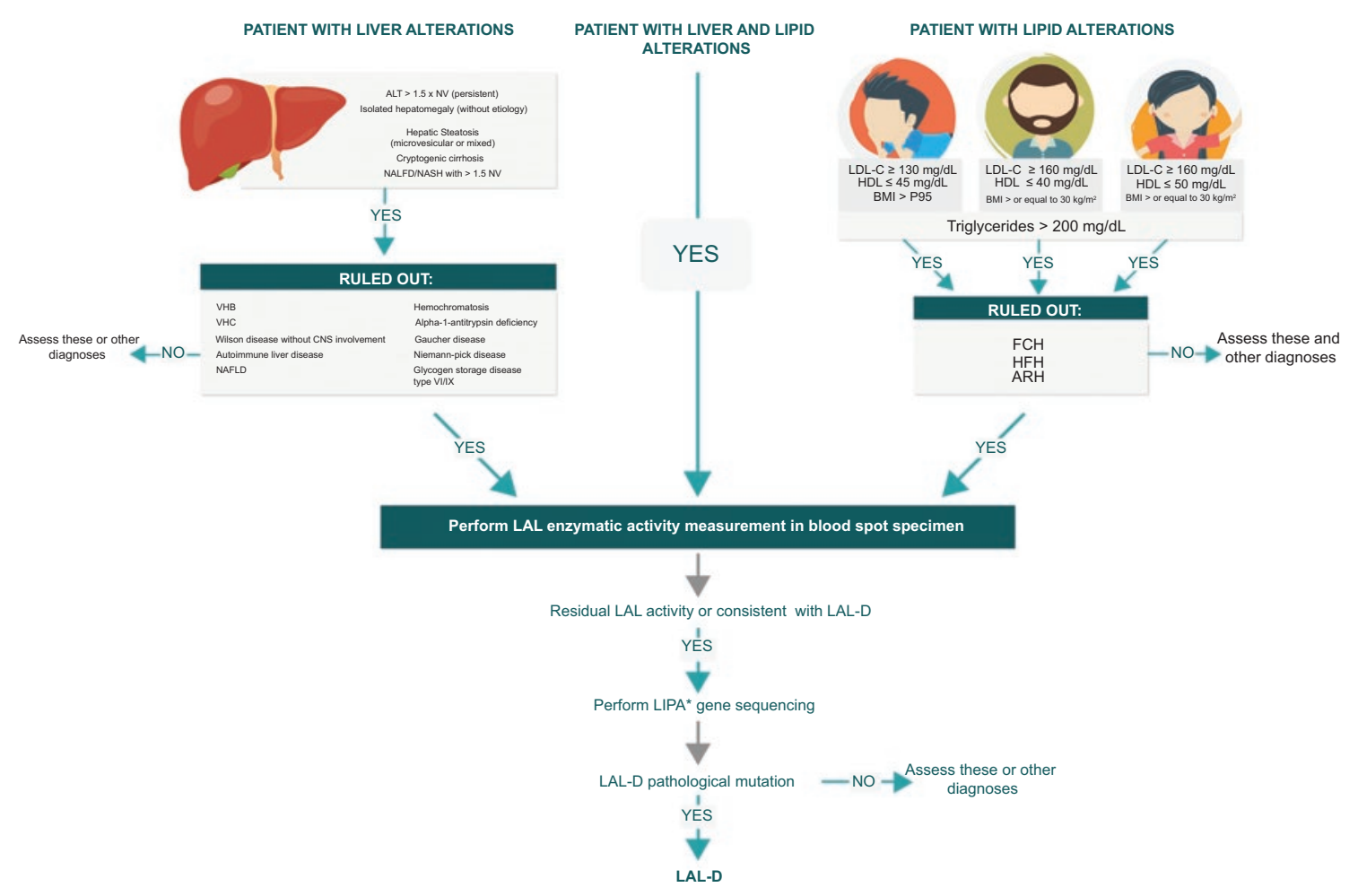

Figure 2. Guideline for lysosomal acid lipase clinical suspicion. $A L T$ = alanine aminotransferase, $H D L-C=$ high-density lipoprotein cholesterol, $L D L-C=$ low-density lipoprotein cholesterol, $L A L-D$ - lysosomal acid lipase deficiency, NAFLD = non-alcoholic fatty liver disease, $A R H=$ autosomal recessive hypercholesterolemia, $\mathrm{HFH}=$ heterozygous familial hypercholesterolemia, $F C H=$ familial combined hyperlipidemia, $B M I=b o d y$ mass index, $L A L=$ lysosomal acid lipase, $C N S=$ central nervous system, $H B V=$ hepatitis $B$ virus, $H C V=$ hepatitis $C$ virus, $N V=$ normal value. ${ }^{*}$ According to availability.

or dried blood spot leukocytes. ${ }^{5,12,34}$ Molecular analysis with LIPA gene regions genetic sequencing is used to identify point and deep intronic mutations or rearrangements. ${ }^{12}$ On the other hand, the dried blood spot technique determines LAL's in vitro activity in the presence of substrates (oleate, palmitate, etc.) modified with fluorochrome (4-methylumbelliferone), which allows quantification of the amount of released product through emission spectroscopy or fluorimetry. ${ }^{6,12,35}$

Given that the presence of other lipases in blood can interfere with the measurement, a LAL inhibitor called Lalistat $2^{\circledR}$ is used (Chemical Tools, South Bend, IN, USA). ${ }^{35}$ LAL activity is determined by comparing total lipase activity with lipase activity in the presence of the inhibitor; the difference between both is attributable to the LAL enzyme. Reduced values of enzymatic activity according to the ranges established by the laboratory are considered diagnostic of LAL-D. Complete sequencing of the LIPA gene coding region allows the identification of mutations that cause the disease. Most patients are homozygotes or compound heterozygotes; ${ }^{4.12,35}$ however, some can have intronic mutations or other variants that may not be detected by sequencing. Therefore, the method of choice for diagnosis is enzymatic activity measurement, and molecular tests are considered complementary. ${ }^{4}$

\section{Treatment}

In the past, the treatment consisted only in prevention of disease complications. Lifestyle changes were recommended and treatment with lipid-lowering agents (statins) for the management of hypercholesterolemia. Statins decrease LDL levels; however, they do not generate changes in the development of liver fibrosis., ${ }^{4,6,12,36,37}$

Bone marrow transplantation has been used in cases of LAL-D with early diagnosis to prevent cardiovascular complications or in infants with rapidly progressive LAL-D; however, further studies are still needed to rigorously assess this strategy..$^{3,4,6,12}$ In turn, liver transplantation is the treatment indicated for liver failure, and should be performed in conjunction with bone marrow transplant bone due to the risk of disease recurrence. So far, follow-up of these patients does not allow drawing conclusions on the efficacy of this intervention in LAL-D. $2,6,36,38,39$

Enzyme replacement therapy is currently used, which seeks to restore physiological levels of the enzyme and 
thus prevent the accumulation of cholesterol and triglyceride esters by delaying disease progression. ${ }^{4,12}$ Replacement can be carried out with recombinant human lysosomal acid lipase (rhLAL) enzyme or recombinant sebelipase-alfa (Kanuma ${ }^{\circledR}$, Alexion Pharmaceuticals), a glycoprotein that contains $37853-55-k D a$ amino acids, six $\mathrm{N}$-linked glycosylation sites and is extracted from chicken eggs. ${ }^{5.40-42}$

This drug penetrates different cells (Kupffer cells and hepatocytes, among others) through the mannose-6-phosphate receptors; once inside, the recombinant enzyme replaces $\mathrm{LAL}$, hydrolyzing cholesterol and triglyceride esters within the lysosome to reverse its effects. ${ }^{3,12,43}$ It has been used in biomodels with rodents, where it has been observed to correct abnormalities associated with this condition: it decreases the lipid content at the hepatic level, splenomegaly, transaminase levels and atherosclerosis. ${ }^{2,43-46}$ Six studies have been carried out to assess the efficacy and safety of this drug in infants with LAL-D (LAL-CL03 and LALCL08) and in pediatric and adult patients with LAL-D (LAL-CL01, LAL-CL04 and LAL-CL02). ${ }^{3,6,29,41,47}$ In clinical trials in humans, it has been shown to decrease blood liver enzymes, liver volume and fat at the liver level; in addition, it has achieved improvements in plasma lipid levels (LDL and HDL), with increases in HDL-cholesterol and decreases in LDL-cholesterol. 2,3,6,12,29,40,47 Furthermore, phase I and II clinical trials were performed in adults with LAL-D to whom $0.35,1$ or $3 \mathrm{mg} / \mathrm{kg}$ intravenous sebelipase-alpha was applied for seven days; a decrease in transaminase levels was observed. ${ }^{41,43}$

The same patients from the above study were subsequently included in a 52-week follow-up investigation; all were started with the same pharmacological management with sebelipase-alfa and, at 15 days, an adjustment to 1 or $3 \mathrm{mg} / \mathrm{kg}$ was applied. Decreases were observed in total cholesterol, LDL-cholesterol and triglycerides, associated with other findings such as reduction of the fat fraction and liver volume. .11,48 $^{4}$ Finally, in the ARISE phase III study, pediatric ( $\geq 4$ years) and adult patients with LAL-D were included and randomly received sebelipase-alpha $(1 \mathrm{mg} / \mathrm{kg}$ every two weeks, $n=36$ ) or placebo $(n=30)$ for 20 weeks; among the results, decreases in transaminases and LDL-cholesterol were observed in the group managed with sebelipase-alfa in comparison with the group that only received placebo. ${ }^{29}$

Enzyme replacement therapy (sebelipase-alfa) in patients younger than six months starts with $1 \mathrm{mg} / \mathrm{kg}$ once weekly and should be escalated to $3 \mathrm{mg} / \mathrm{kg}$ depending on the patient. In those with late-onset LAL-D, the dose is $1 \mathrm{mg} / \mathrm{kg}$ every 15 days and should not be adjusted if they are older than 65 years or if they have kidney or liver failure. ${ }^{3.43}$ Adverse effects reported that are not attributable to the medication include nausea, headache, diarrhea and abdominal pain. $4,6,29,40,41$

\section{Follow-up}

Camarena et al. state that patients should have strict clinical and paraclinical follow-up (every three months during the first year). In the first visit, patient baseline status should be assessed with liver biopsy, diagnostic imaging and paraclinic tests (blood count, coagulation tests, lipid and liver profile). ${ }^{11}$ Subsequently, treatment response should be evaluated with clinical and paraclinical serial assessment. As for specific follow-up in children, growth and nutritional status should be monitored, while in adults, follow-up should be carried out according to disease severity. ${ }^{49}$

\section{Differential diagnosis}

LAL-D has clinical characteristics that can be mistaken for other diseases, such as non-alcoholic hepatic steatosis, non-alcoholic fatty liver disease, metabolic syndrome, autosomal recessive hypercholesterolemia (MIM: 603813), sitosterolemia (MIM: 210250) or familial hypercholesterolemia (MIM: 143890).,5,11,50

Regarding the differences between familial hypercholesterolemia and LAL-D, the former is an autosomal dominant genetic disease, i.e. patients must have a family history of the condition. On the other hand, the lipid profile shows higher levels of LDL and HDL in familial hypercholesterolemia. ${ }^{4,5}$ In general, unlike patients with LAL-D, patients with metabolic syndrome have obesity. ${ }^{4}$ As for the differences between non-alcoholic fatty liver disease and LAL-D, patients usually have obesity or overweight and findings in the liver biopsy are different: in most cases, macrovesicular steatosis is observed. ${ }^{50}$

\section{Conclusions}

LAL-D is a poorly prevalent and underdiagnosed disease, generated by mutations in the LIPA gene. In this pathology, lipid metabolism is affected at the lysosomal level and is characterized by systemic and progressive accumulation of esterified cholesterol and triglycerides. The presentation phenotype depends on 
the degree of enzymatic activity; when it is nil, LAL-D occurs early and severely, with high mortality at one year of life. The late presentation has a heterogeneous phenotype: most patients develop chronic liver disease and, some, early cardiovascular disease.

Diagnosis represents a challenge, since clinical manifestations overlap with those of other diseases. LAL-D should be suspected in the presence of persistent liver or lipid alterations without a clear cause. Early diagnosis is essential for management with enzyme replacement therapy, which has been shown to improve lipid and liver parameters, as well as survival of infants with rapidly progressing disease ${ }^{51}$ However, the actual prevalence of this disorder is thought to be underestimated given the absence of knowledge and limitation of diagnostic tests for this disease, and the conduction of prevalence studies in Latin America is therefore necessary.

\section{References}

1. Aslanidis C, Ries S, Fehringer P, Büchler C, Klima H, Schmitz G. Genetic and biochemical evidence that CESD and Wolman disease are distinguished by residual lysosomal acid lipase activity. Genomics. 1996; 33:85-93.

2. Rader DJ. Lysosomal acid lipase deficiency: a new therapy for a genetic lipid disease. N Engl J Med. 2015;373:1071-1073.

3. Frampton JE. Sebelipase alfa: a review in lysosomal acid lipase deficiency. Am J Cardiovasc Drugs. 2016;16:461-468

4. Reiner Ž, Guardamagna O, Nair D, Soran H, Hovingh K, Bertolini S, et al. Lysosomal acid lipase deficiency: an under-recognized cause of dyslipidaemia and liver dysfunction. Atherosclerosis. 2014;235:21-30.

5. Wierzbicka-Rucińska A, Jańczyk W, Ługowska A, Lebensztejn $D$, Socha P. Diagnostic and therapeutic management of children with lysosomal acid lipase deficiency (LAL-D). Review of the literature and own experience. Dev Period Med. 2016;20:212-215.

6. Su K, Donaldson E, Sharma R. Novel treatment options for lysosoma acid lipase deficiency: critical appraisal of sebelipase alfa. Appl Clin Genet. 2016;9:157-167

7. Grabowski G. Therapy for lysosomal acid lipase deficiency: replacing a missing link. Hepatology. 2013;58(3):850-852.

8. Fasano T, Pisciotta L, Bocchi L, Guardamagna O, Assandro P Rabacchi C, et al. Lysosomal lipase deficiency: molecular characterization of eleven patients with Wolman or cholesteryl ester storage disease. Mol Genet Metab. 2012;105(3):450-456.

9. Jones SA, Valayannopoulos V, Schneider E, Eckert S, Banikazemi M, Bialer M, et al. Rapid progression and mortality of lysosomal acid lipase deficiency presenting in infants. Genet Med. 2015;18:425-428.

10. Ramírez CM, López AM, Turley SD. Lysosomal acid lipase activity: a tool for the detection and management of fatty liver disease? EBioMedicine. 2015;2:638-639.

11. Camarena C, Aldamiz-Echevarría LJ, Polo B, Barba-Romero MA, García I, Cebolla JJ, et al. Actualización en deficiencia de lipasa ácida lisosomal: diagnóstico, tratamiento y seguimiento de los pacientes. Med Clin. 2017;148:429.e1-429.e10.

12. Bay L, Cañero-Velasco C, Ciocca M, Cotti A, Cuarterolo M, Fainboim A et al. Enfermedad hepática y dislipemia como manifestación de deficiencia de lipasa acida lisosomal (LAL-D). Aspectos clínicos, diagnósticos y nuevo tratamiento. Actualización. Arch Argent Pediatr. 2017; 115:287-293.

13. Reynolds T. Cholesteryl ester storage disease: a rare and possibly treatable cause of premature vascular disease and cirrhosis. J Clin Pathol. 2013;66:918-923.

14. Scott SA, Liu B, Nazarenko I, Martis S, Kozlitina J, Yang Y, et al. Frequency of the cholesteryl ester storage disease common LIPA E8SJM mutation (c.894G>A) in various racial and ethnic groups. Hepatolology. 2013;58:958-965.

15. Stitziel NO, Fouchier SW, Sjouke B, Peloso GM, Moscoso AM, Auer PL, et al. Exome sequencing and directed clinical phenotyping diagnose cholesterol ester storage disease presenting as autosomal recessive hypercholesterolemia. Arterioscler Thromb Vasc Biol. 2013;33:2909-2914.
16. Muntoni S, Wiebusch H, Jansen-Rust M, Rust S, Seedorf U, Schulte H, et al. Prevalence of cholesteryl ester storage disease. Arterioscler Thromb Vasc Biol. 2007;27:1866-1868.

17. The Human Gene Mutation Database [sitio web]. HGMD gene result. Gales, Reino Unido: Institute of Medical Genetics in Cardiff; 2017.

18. Tanaka A. Acid lipase deficiency: Wolman disease and cholesteryl ester storage disease. Nihon Rinsho. 1995;53:3004-3008.

19. Reference GH [sitio web]. Lysosomal acid lipase deficiency. EE. UU.: Genetics Home Reference; 2017.

20. Santillán-Hernández Y, Almanza-Miranda E, Xin WW, Goss K, Vera-Loaiza A, Gorráez-De la Mora MT, et al. Novel LIPA mutations in Mexican siblings with lysosomal acid lipase deficiency. World J Gastroenterol. 2015;21:1001-1008.

21. Asociación Española Déficit de Lipasa Ácida Lisosomal [sitio web]. Prevalencia. Déficit de lipasa ácida lisosomal. España: Asociación Española Déficit de Lipasa Ácida Lisosomal; 2019.

22. Valles-Ayoub Y, Esfandiarifard S, No D, Sinai P, Khokher Z, Kohan M, et al. Wolman disease (LIPA p.G87V) genotype frequency in people of Iranian-Jewish ancestry. Genet Test Mol Biomarkers. 2011:15:395-398.

23. Vespasiani-Gentilucci U, Gallo P, Piemonte F, Riva E, Porcari A, Vorini $F$, et al. Lysosomal acid lipase activity is reduced both in cryptogenic cirrhosis and in cirrhosis of known etiology. PloS One. 2016; 11:e0156113.

24. Mendoza-Durán M, Pastor-Rosado J, Fajardo-Giménez M, Vázquez-Pigueiras I, Canals-Candela F, Abad-Linares J. Enfermedad de depósito de ésteres de colesterol. Actualización del diagnóstico y el tratamiento. Acta Pediatr Esp. 2015;73:e31-40.

25. Saito S, Ohno K, Suzuki T, Sakuraba H. Structural bases of Wolman disease and cholesteryl ester storage disease. Mol Genet Metab. 2012 Feb;105:244-248.

26. Xanthomatosis G, Calcified W. Glands Early Finding. Reported Pic; 2015.

27. Drebber U, Andersen M, Kasper HU, Lohse P, Stolte M, Dienes HP. Severe chronic diarrhea and weight loss in cholesteryl ester storage disease: a case report. World J Gastroenterol. 2005;11:2364-2366.

28. Zhang B, Porto AF. Cholesteryl ester storage disease: protean presentations of lysosomal acid lipase deficiency. J Pediatr Gastroenterol Nutr. 2013;56:682-685

29. Burton BK, Deegan PB, Enns GM, Guardamagna O, Horslen S, Hovingh GK, et al. Clinical features of lysosomal acid lipase deficiency. J Pediatr Gastroenterol Nutr. 2015;61:619-625.

30. Bernstein DL, Hülkova H, Bialer MG, Desnick RJ. Cholesteryl ester storage disease: Review of the findings in 135 reported patients with an underdiagnosed disease. J Hepatol. 2013:58:1230-1243.

31. Morris GE, Braund PS, Moore JS, Samani NJ, Codd V, Webb TR. Coronary artery disease-associated LIPA coding variant rs1051338 reduces lysosomal acid lipase levels and activity in lysosomes. Arterioscler Thromb Vasc Biol. 2017;37:1050-1057.

32. Hůlková H, Elleder M. Distinctive histopathological features that support a diagnosis of cholesterol ester storage disease in liver biopsy specimens. Histopathology. 2012;60:1107-1113.

33. Ivashkin V, Zharkova M. Cholesteryl ester crystals in lysosomal acid lipase deficiency. N Engl J Med. 2017;376:e14.

34. Pisciotta L, Fresa R, Bellocchio A, Pino E, Guido V, Cantafora A, et al. Cholesteryl Ester Storage Disease (CESD) due to novel mutations in the LIPA gene. Mol Genet Metab. 2009;97:143-148.

35. Hamilton J, Jones I, Srivastava R, Galloway P. A new method for the measurement of lysosomal acid lipase in dried blood spots using the inhibitor Lalistat 2. Clin Chim Acta. 2012;413:1207-1210.

36. Sreekantam S, Nicklaus-Wollenteit I, Orr J, Sharif K, Vijay S, McKiernan PJ, et al. Successful long-term outcome of liver transplantation in late-onset lysosomal acid lipase deficiency. Pediatr Transplant. 2016;20:851-854.

37. Iverson S, Cairns S, Ward C, Fensom A. Asymptomatic cholesteryl ester storage disease in an adult controlled with simvastatin. Ann Clin Biochem. 1997;34:433-436

38. Riva S, Spada M, Sciveres M, Minervini M, Cintorino D, Maggiore G, et al. Hepatocarcinoma in a child with cholesterol ester storage disease. Dig Liver Dis. 2008;40:784.

39. Jones S, Bernstein D, Bialer M, Dhawan A, Hendriksz C, Whitley CB, et al. Severe and rapid disease course in the natural history of infants with lysosomal acid lipase deficiency. Mol Genet Metab. 2014; 111:S57-S58

40. Block RC, Razani B. Options to consider when treating lysosomal acid lipase deficiency. J Clin Lipidol. 2016:10:1280-1281.

41. Balwani M, Breen C, Enns GM, Deegan PB, Honzík T, Jones S, et al. Clinical effect and safety profile of recombinant human lysosomal acid lipase in patients with cholesteryl ester storage disease. Hepatology. 2013;58:950-957.

42. Boletín mensual de la Agencia Española de Medicamentos y Productos Sanitarios junio de 2015. España: AEMPS; 2015.

43. European Medicines Agency. Assessment report. Reino Unido: European Medicines Agency/Committee for Medicinal Products for Human Use; 2015. 
44. Rutkowski JV, Burt AD, Leavitt MC, Hu W, Canty D, Quinn AG. Co-localization of macrophage aggregation and fibrosis in a rat model of lysosomal acid lipase (LAL) deficiency and the effects of enzyme replacement with SBC-102. Mol Genet Metab. 2013;108:S80-S81.

45. Rutkowski J, Burt AD, Leavitt M, Hu W, Canty D, Quinn AG. Recombinant human lysosomal acid lipase decreases hepatic macrophage aggregates and colocalized fibrosis in a rat model of lysosomal acid lipase deficiency. hepatology. Hepatology. 2012;56:858A.

46. Thelwall PE, Smith FE, Leavitt MC, Canty D, Hu W, Hollingsworth KG, et al. Hepatic cholesteryl ester accumulation in lysosomal acid lipase deficiency: non-invasive identification and treatment monitoring by magnetic resonance. J Hepatol. 2013;59:543-549.

47. Shirley M. Sebelipase alfa: first global approval. Drugs. 2015;75:1935-1940.
48. Valayannopoulos V, Malinova V, Honzík T, Balwani M, Breen C, Deegan PB, et al. Sebelipase alfa over 52 weeks reduces serum transaminases, liver volume and improves serum lipids in patients with lysosomal acid lipase deficiency. J Hepatol. 2014;61:1135-1142.

49. Hoffman EP, Barr ML, Giovanni MA, Murray MF. Lysosomal acid lipase deficiency. En: Pagon RA, Adam MP, Ardinger HH, Wallace SE, Amemiya A, Bean LJ, et al. , editores. GeneReviews [sitio web]. EE. UU. University of Washington; 1993.

50. Himes RW, Barlow SE, Bove K, Quintanilla NM, Sheridan R, Kohli R. Lysosomal acid lipase deficiency unmasked in two children with nonalcoholic fatty liver disease. Pediatrics. 2016;138:pii.

51. Botero V, García VH, Gómez-Duarte C, Aristizabal AM, Arrunategui AM, Echeverri GJ, et al. Lysosomal acid lipase deficiency, a rare pathology: the first pediatric patient reported in Colombia. Am J Case Rep. 2018;19:669-672. 